\title{
Crystalline Leghemoglobin
}

\section{Purification Procedure}

\author{
NILS ELLFOLK*
}

Medicinska Nobelinstitutet, Biokemiska avdelningen, Stockholm, Sweden

\begin{abstract}
A procedure is described for the purification of leghemoglobin to give the two main components in a crystalline state. The different components were isolated by chromatography using diethylaminoethyl cellulose as adsorbent. The main components were crystallised from slightly acid ammonium sulphate solution. Both of the crystalline components were found to be electrophoretically homogeneous in long-time electrophoresis runs at two different $\mathrm{pH}$ values. The electrophoretically faster component contained $0.32 \%$ iron, and the slower one $0.29 \%$ iron.
\end{abstract}

Tn 1938 Pietz $^{1}$ reported the observation of a red pigment in the root nodules Iof!Vicia Faba. He assumed this substance to be 5,6-quinone-2,3-dihydroindole-2-carboxylic acid, the red oxidation product of tyrosin or dihydroxyphenylalanin. In $1939 \mathrm{Kubo}^{2}$ extracted the pigment from soya bean root nodules, and fractionated it with ammonium sulphate. On the basis of his studies, Kubo concluded that the red pigment was a hemoprotein similar to hemoglobin. Burris and Haas ${ }^{3}$ definitely showed that the pigment was a hemin compound, but disagreed with its classification as a hemoglobin-like compound. Keilin and Wang ${ }^{4}$, as well as Virtanen ${ }^{5}$, idependently confirmed the results of Kubo concerning the hemoglobin nature of the pigment. The same conclusion was later reached by Little and Burris ${ }^{6}$. Virtanen et al. ${ }^{7}$ proposed that the name leghemoglobin be used for the hemoglobin-like pigments in the root nodules of leguminous plants. This name will be used in this paper.

Ellfolk and Virtanen ${ }^{8}$ found that leghemoglobin could be fractionated by electrophoresis to give two components of equal concentration but of different hemin content. This was later confirmed by Thorogood ${ }^{9}$, who also was able to find a third component, and probably a fourth one.

* Permanent address: Research Laboratories of the State Alcohol Monopoly, Helsinki, Finland. 
The experiments to be reported here have been carried out in order to develop a technique to purify the different components. All the present studies on leghemoglobin have been done on the oxidized form, i.e. leghemiglobin. A preliminary report of these results has recently been published ${ }^{10}$.

\section{MATERIAL}

Soya bean root nodules. The soya beans were inoculated with root nodule bacteria (Rizobium leguminosarum), and grown in a green-house with a relative humiditiy of $70-80 \%$, and a temperature of $25^{\circ} \mathrm{C}$. The culture medium was sea sand. The watering solution ( $\mathrm{pH} 6.5$, and free from chemically bound nitrogen) had the following composition: $3.6 \mathrm{~g} \mathrm{MgSO} 4.7 \mathrm{H}_{2} \mathrm{O}, 4.5 \mathrm{~g} \mathrm{KCl}, 4.2 \mathrm{~g} \mathrm{KH}_{2} \mathrm{PO}_{4}, 4.0 \mathrm{~g} \mathrm{CaSO}_{4}, 25 \mathrm{mg}$ ferric citrate, $0.55 \mathrm{mg}$

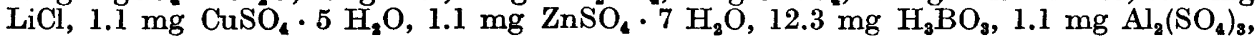
$0.55 \mathrm{mg} \mathrm{SnCl} l_{2}, 0.55 \mathrm{mg} \mathrm{KI}, 7.7 \mathrm{mg} \mathrm{MnCl} \mathrm{H}_{2} \cdot 4 \mathrm{H}_{2} \mathrm{O}, 1.1 \mathrm{mg} \mathrm{NiCl} \cdot 6 \mathrm{H}_{2} \mathrm{O}, 1.1 \mathrm{mg} \mathrm{CoCl} 2 \cdot 6$ $\mathrm{H}_{2} \mathrm{O}$, $0.55 \mathrm{mg} \mathrm{KBr}$, and 60 liters of tap water. The plants were usually harvested after the first blossoms appeared (after about six weeks). The nodules were used immediately, or stored at $-20^{\circ} \mathrm{C}$.

Ion exchange material. An adsorbent (CM-W) ${ }^{11}$ with carboxyl groups was prepared from Whatman cellulose powder, and an absorbent with diethylaminoethyl (DEAE) groups was prepared from Solka Flok as well as from Whatman cellulose powder ${ }^{11}$. The product prepared from Solka Flok was preferred for column chromatography because it resulted in a faster-flowing column.

\section{METHODS}

Iron determination. Iron was determined spectrophotometrically by the sulphosalicylic acid method ${ }^{12}$. Combustion of the material was performed with sulphuric acid and hydrogen peroxide. The intensity of the color that was formed in ammoniacal solution with sulphosalicylic acid was measured at $424 \mathrm{~m} \mu$ in the spectrophotometer.

Pyridine hemochromogen was determined according to Paul, Theorell and Åkeson ${ }^{13}$.

Column chromatography. Dry ion exchange cellulose was dispersed with rapid stirring in the buffer that was used for the first elution, and was allowed to settle. The buffer solution was changed several times until no $\mathrm{pH}$ change occurred. $10 \mathrm{~cm}$ high columns were prepared by allowing the slurry to settle under gravity in glass tubes. Tubes with an internal diameter of $1 \mathrm{~cm}$ were used for preliminary studies, whereas for preparative runs, tubes with an internal diameter of $2.5 \mathrm{~cm}$ were used. The chromatography was always performed at $+3^{\circ} \mathrm{C}$.

Electrophoresis. This was carried out at $0.6^{\circ} \mathrm{C}$ in a Tiselius electrophoresis apparatus (Beckman/Spinco Model H Electrophoresis-Diffusion Instrument). For most of the runs the $11 \mathrm{ml}$ cell was used, though in some experiments the $2 \mathrm{ml}$ cell was used. As the source of illumination, the $644 \mathrm{~m} \mu$ spectral line from a $\mathrm{Cd}-\mathrm{Hg}$ vapor lamp was isolated by means of a red filter. Before electrophoresis the protein was dialyzed for $48 \mathrm{~h}$ against 2 liters of buffer at $+3^{\circ} \mathrm{C}$.

The mobility was calculated by a simple equation $u=S / F$, where $S$ is the apparent speed of the boundary, and $F$ is the potential gradient. The latter quantity is calculated from the' equation $F=i / q x$ where $i$ is the current in amperes, $q$ is the cross-section of the electrophoresis cell in $\mathrm{cm}^{2}$ and $x$ is the specific conductance of the solutions.;

\section{RESULTS}

Different methods were tried in an effort to separate the different components of leghemoglobin. Repeated fractionations with ammonium sulphate at small increments gave no separation of the different components as determined by paper electrophoresis. Fractionation with acetone also was unsuc- 
cessful. In addition, preparative electrophoresis on a cellulose column ${ }^{14}$, high voltage electrophoresis on paper, ion exchange chromatography on both carboxymethyl cellulose and diethylaminoethyl-cellulose were tested for their ability to separate the different components of leghemoglobin. Of these methods, only ion exchange chromatography on DEAE-cellulose could be successfully used on a preparative scale. The column was prepared at $\mathrm{pH} 5.2$, which is slightly higher than the isoelectric points of the components. A lower $\mathrm{pH}$ was not used because of the danger of denaturation of the protein on the column. The following procedure was used for preparing crystalline fractions of the two main components:

Extraction. Frozen nodules were ground in a mortar with a small amount of distilled water, and centrifuged at $+3^{\circ} \mathrm{C}$. The supernatant solution contained most of the leghemoglobin of the nodules. In order or remove all the leghemoglobin, the precipitate was extracted a second and third time with distilled water. The extracts were pooled, and fractionated at room temperature with ammonium sulphate.

Ammonium sulphate fractionation. Solid ammonium sulphate was added until the solution was $55 \%$ saturated with respect to ammonium sulphate. The $\mathrm{pH}$ of the solution was kept just above $\mathrm{pH} 5$ by the addition of ammonia. After $1 \mathrm{~h}$, the solution was centrifuged, and the precipitate was discarded. To the clear red supernatant solution, solid ammonium sulphate was added to a saturation of $80 \%$. After $1 \mathrm{~h}$, the crude leghemoglobin was centrifuged down, and the clear, yellow supernatant solution was discarded. The precipitate was dissolved in a small amount of $0.1 \mathrm{M}$ phosphate buffer at $\mathrm{pH} 8$. Further fractionation with ammonium sulphate was avoided because it was evident that the micro air bubbles formed by addition of solid ammonium sulphate had a denaturating effect on the heminprotein.

Dialysis. Before the resulting preparation was fractionated on the ion exchange column, the remaining ammonium sulphate had to be removed by dialysis. The dissolved precipitate was dialyzed for $6 \mathrm{~h}$ against $10^{-4} \mathrm{M}$ phosphate buffer ( $\mathrm{pH} 8$ ) and for $24 \mathrm{~h}$ against distilled water.

Column chromatography. For preparative work, the column $(2.5 \mathrm{~cm}$ in diameter) was loaded with 100 to $150 \mathrm{mg}$ of protein in 10 to $15 \mathrm{ml}$ of salt-free solution. All of the protein remained on top of the column as a sharp brown band (Fig. 1, column I). The eluation was started with acetate buffer $\mathrm{pH} 5.2$, $\mu=0.01$. With this ionic strength one band moved down the column and could easily be separated (Fig. 1, $a$ ). A very faint, broad band (Fig. 1, $b$ ) followed the first band. When fraction $b$ had left the column, the ionic strength of the eluation buffer was increased to $0.02-0.03$ by the addition of sodium chloride. At this ionic strength a very sharp band, followed by a small sharp band, moved down the column (Fig. 1, $c$ and $d$ ). On the top of the column there remained a brown band (Fig. 1,e) which could not be quantitatively eluted even with buffers of high ionic strength (sodium chloride concentration increased to $3 \mathrm{M}$ ). The color of the bands was not uniform during the eluation procedure, but showed a change from red-brown to green. This was found not to depend upon the presence of any oxidized product of leghemiglobin (choleglobin) but on the formation of a green complex between leghemiglobin and the acetic acid of the eluant.

Acta Chem. Scand. 14 (1960) No. 3 


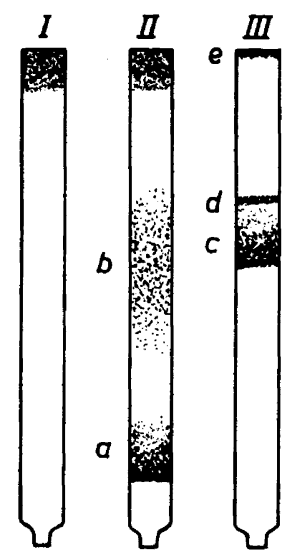

Fig. 1. Column chromatograms of leghemoglobin. Leghemoglobin adsorbed on the top of the DEAE-cellulose column (I). The chromatogram was developed with acetate buffer of $\mathrm{pH} 5.2, \mu=0.01$ (II), and $\mu=0.03$ (III).

To concentrate the rather dilute fractions, the solutions were dialyzed against distilled water, and the proteins were adsorbed on the top of a short column $(1.5-2 \mathrm{~cm}$ high). The proteins were eluted from the column by a small volume of $0.1 \mathrm{M}$ phosphate buffer.

Crystallisation. The two main fractions of leghemoglobin were crystallised at $+3^{\circ} \mathrm{C}$ by dialysing a salt-free solution of each protein against an increasing concentration of ammonium sulphate. The dialysis was started against $55 \%$ saturated ammonium sulphate at $\mathrm{pH}$ 6. The degree of saturation was increased by inccrements of $2.5 \%$ every $12 \mathrm{~h}$, while the $\mathrm{pH}$ was maintained at 6 . At $60 \%$ saturation, the $\mathrm{pH}$ was lowered to about 5 by the addition of sulphuric acid. The first crystals were usually obtained about $24 \mathrm{~h}$ later, after which the ammonium sulphate saturation was increased step-wise to $65 \%$.

Crystallisation of component $a$ was also achieved by adding saturated ammonium sulphate solution of $\mathrm{pH} 5$ to a concentrated solution of the protein until a clear "silkiness" was obtained. After keeping the solution at $+3^{\circ} \mathrm{C}$ for several days, crystals were formed. For some reason, crystals were not obtained from component $c$ by this technique, although a silkiness could easily be produced. Fig $2 \mathrm{~A}$ shows a photomicrograph (phase-contrast microscope) of separate needles of compound $a$ and demonstrates the homogeneity of the preparation, whereas Fig. 2B shows a photomicrograph (phase-contrast microscope) of an association of these crystals to form a cluster of needles. Fig. 2C shows a photomicrograph of cyrstals of component $c$ taken with an ultraviolet light microscope illuminated with light of $2750 \AA$. The crystals are in the form of needles associated to form rosettes.

The photomicrographs show that the crystals of the two components have very similar forms, but that they differ in the way they associate. Both crystalline components were clearly double refracting in plane polarized light, except for the crystals in Fig. 2A which evidently were too thin to produce a double refraction.

Electrophoresis. The fractions that were crystallised ( $a$ and $c$ ), as well as fractions $b$ and $d$, were examined in the Tiselius apparatus at two different $\mathrm{pH}$ 
A

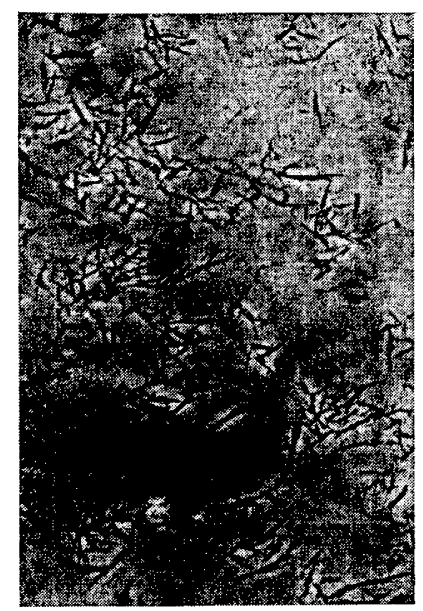

C

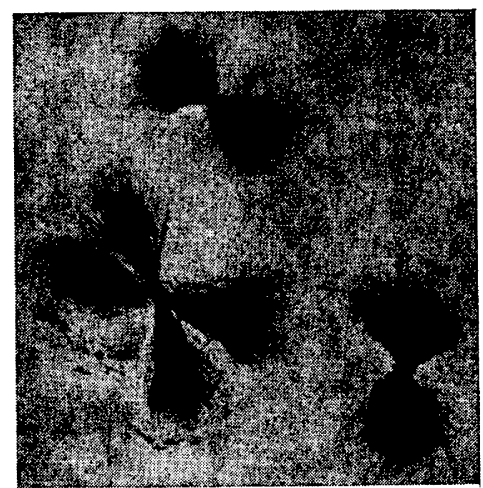

B

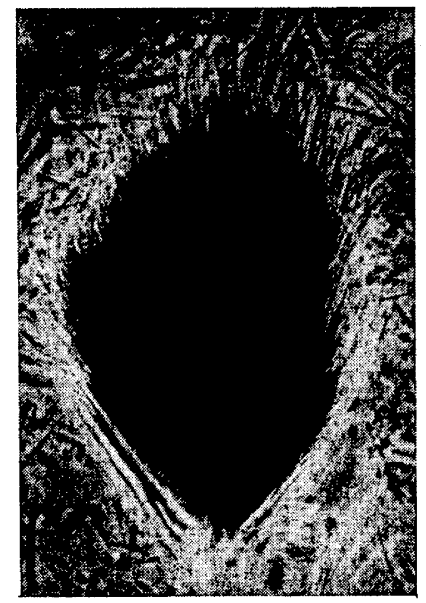

Fig. 2. Crystalline leghemoglobin.

A. Homogeneous small needles of fraction $a, 150 \times$

B. An association of needles of fraction $a, 210 \times$

C. An association of needles of fraction $c, 650 \times$

values. At $\mathrm{pH} 6.05, \mu=0.1$ (phosphate buffer), and at $\mathrm{pH} 9.0, \mu=0.1$ (veronal buffer), the two main crystallised fractions appeared to be homogeneous as determined by long run electrophoresis. Fig. 3 shows the electrophoretic patterns at $\mathrm{pH}$ 6.05. Similar patterns were obtained at $\mathrm{pH} 9.0$ after $470 \mathrm{~min}$. At both $\mathrm{pH}$ values the direction of migration was anodic. It can be seen that fraction $a$ represents the electrophoretically slower component and fraction $c$ the faster one.

During electrophoresis of fraction $b$ at $\mathrm{pH} 6.05$, only a very broad boundary with no distinct separate peaks was found, thereby indicating the presence of several different components. Electrophoresis of fraction $d$ at $\mathrm{pH} 6.05$ showed the presence of two components, one of which had the same mobility as fraction $c$, while the other had a slightly higher mobility.

Acta Chem. Scand. 14 (1960) No. 3 


\section{1}

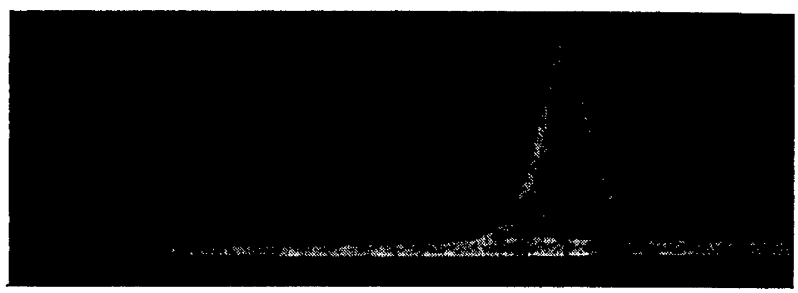

2

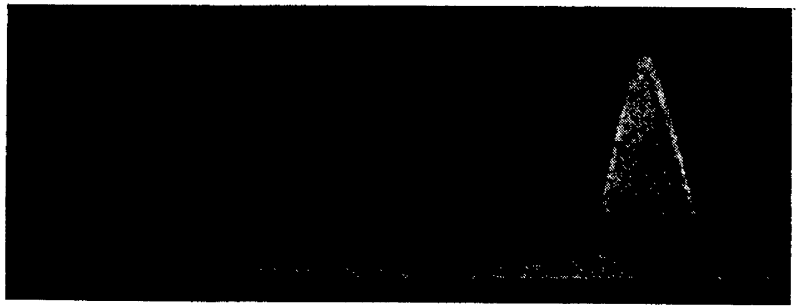

Fig. 3. Electrophoretic patterns of leghemoglobin; $\mathrm{pH} 6.05, \mu=0.1 F=6.75 \mathrm{~V} / \mathrm{cm}$, descending boundaries.

1) $a, t=620 \mathrm{~min}$.

2) $c, t=490 \mathrm{~min}$.

Iron content. Simultaneous iron and dry matter determinations were carried out on aliquots of the two main components. An average iron content of $0.32 \%$ was found for the electrophoretically faster component (component $c$ ), while a value of $0.29 \%$ was found for the slower component (component $a$ ).

Absorption spectra. The spectra of the components of leghemoglobin dissolved in acetate buffer were different from the spectra when the leghemoglobin was dissolved in phosphate buffer. The difference in the spectra was found to be caused by the formation of a green-colored reversible complex between leghemoglobin and acetate. Compared with the typical acid methemoglobin spectrum found for all of the different components $(a-d)$, the spectrum of the acetate complex showed a typcial increase in absorption of the $625 \mathrm{~m} \mu$ band accompanied by a slight shift in the absorption maximum toward the violet part of the spectrum. No quantitative differences were found in the methemoglobin spectra of the two main components ( $a$ and $c$ ). For fractions $b$ and $d$, the maximum absorption in the region of $625 \mathrm{~m} \mu$ was somewhat flattened, probably because of the presence of bile pigments. The sodium chloride extract of fraction $e$ showed no maximum or minimum in the visible part of the spectrum, but showed a maximum corresponding to the Soret band in the ultraviolet region of the spectrum. The pyridine hemochromogens of the different components showed a typical peak at $557 \mathrm{~m} \mu$. In the case of fraction $e$, however, the ratio of absorbance at $630 \mathrm{~m} \mu / 557 \mathrm{~m} \mu$ was 0.46 , thereby indicating the presence of a high percentage of bile pigments or other pigments such as polyphenols. 


\section{DISCUSSION}

It has been shown that leghemoglobin can be resolved into four components on a DEAE-cellulose column. The different fractions were eluted from the column in the order of increasing electrophoretic mobility so that the electrophoretically slower component was first eluted from the column. After the four bands were eluted, one band still remained on the top of the column. This evidently consisted of degradation products of leghemoglobin of different degrees of denaturation. This band was not totally eluted even if the ionic strength of the eluant was increased to $\mu=3.0$. The band was not caused by a surface denaturation of the protein on top of the column. Rechromatographed material left no band on the top of the column after eluation of the other components.

The two electrophoretically homogeneous main components have been crystallised for the first time. The electrophoretically faster component was found to have an iron content of $0.32 \%$. This value compares favorably with the value of $0.34 \%$ that was obtained previously when this component was isolated by free electrophoresis ${ }^{15}$. This component was earlier ${ }^{15}$ assumed to represent pure leghemoglobin. The electrophoretically slower component, on the basis of its low iron content, was assumed to be an artefact consisting of pure leghemoglobin and an ironless protein. The present study does not support this assumption, but on the contrary shows that the electrophoretically slower component is a homogeneous individual protein.

Of the two smaller components that represent only a small percentage of the total chromoprotein, at least one represents a homogeneous individual protein (compound $d$ ). It is difficult to decide if component $b$ contains an individual component or if it is a mixture of different oxidation products of fraction $a$. These two smaller components, however, are regularly found in different preparations of leghemoglobin. This might indicate that they represent real individual fractions, even though they contain some oxidized material (choleglobin). The existence of subfractions of proteins is known with other proteins. Crystalline myoglobin has been found to contain a main fraction and at least two subfractions in lower concentration ${ }^{16}$. The differences between these subfractions are very small, probably being caused by the substitution of one or more amino acids by others ${ }^{17}$. In a similar way it is possible that the smaller fractions of leghemoglobin might represent subfractions of the two main components.

Acknowledgments. The author wishes to express his thanks to Professor Hugo Theorell and coworkers at the Department of Biochemistry, Nobel Medical Institute, for valuable discussions and advice during the course of this work. The investigation has been supported by a grant from the State Commission of Natural Sciences (Statens Naturvetenskapliga Kommission) which is gratefully acknowledged.

\section{REFERENCES}

1. Pietz, J. Zentr. Bakteriol. Parasitenk. II, 99 (1938) 1.

2. Kubo, H. Acta Phytochim. (Japan) 11 (1939) 195.

3. Burris, R. H. and Haas, E. J. Biol. Chem. 155 (1944) 227.

4. Keilin, D. and Wang, Y. L. Nature 155 (1945) 227.

Acta Chem. Scand. 14 (1960) No. 3 
5. Virtanen, A. I. Nature 155 (1945) 747.

6. Little, H. N. and Burris, R. H. J. Am. Chem. Soc. 69 (1947) 83.

7. Virtanen, A. I., Jorma, J. and Laine, T. Suomen Kemistilehti, 18 B (1945) 49.

8 Ellfolk, N. and Virtanen, A. I. Acta Chem. Scand. 4 (1950) 1014.

9. Thorogoad, E. Science 126 (1957) 1011.

10. Ellfolk, N. Acta Chem. Scand. 13 (1959) 596.

11. Peterson, E. A. and Sober, A. J. Am. Chem. Soc. 78 (1956) 751.

12. Lorber, F. Biochem. Z. 181 (1927) 391

13. Paul, K. G., Theorell, H. and Åkeson, A. Acta Chem. Scand. 7 (1953) 1284.

14. Flodin, P. and Porath, J. Biochim. et Biophys. Acta 13 (1954) 175.

15. Ellfolk, N. and Virtanen, A. I. Acta Chem. Scand. 6 (1952) 411.

16. Theorell, H. and Alkeson, A. in "Biochemistry of Nitrogen", Ann. Acad. Sci. Fennicae Ser. $A I I$, No. 60 (1955) 303.

17. Akeson, A. and Theorell, H. Arch. Biochem. and Biophys. In press.

Received November 3, 1959. 